\title{
Large subcapsular hematoma following ureteroscopic laser lithotripsy of renal calculi in a spina bifida patient: lessons we learn
}

This article was published in the following Dove Press journal:

International Medical Case Reports Journal

24 August 2016

Number of times this article has been viewed

\author{
Subramanian Vaidyanathan' \\ Azi Samsudin ${ }^{2}$ \\ Gurpreet Singh ${ }^{3}$ \\ Peter L Hughes ${ }^{4}$ \\ Bakul M Soni' \\ Fahed Selmi' \\ 'Regional Spinal Injuries Center, \\ Southport and Formby District \\ General Hospital, Southport, UK; \\ ${ }^{2}$ Department of Urology, Whiston \\ Hospital, Prescot, UK; ${ }^{3}$ Department \\ of Urology, ${ }^{4}$ Department of Radiology, \\ Southport and Formby District \\ General Hospital, Southport, UK
}

Correspondence: Subramanian Vaidyanathan

Regional Spinal Injuries Center, Southport and Formby District General Hospital,

Town Lane, Southport PR8 6PN, UK Email subramanian.vaidyanathan@nhs.net
Introduction: Paraplegic patients are at greater risk of developing complications following ureteroscopic lithotripsy because of urine infection associated with neuropathic bladder, difficulties in access due to altered anatomy of urinary bladder and urethra, spinal curvature, spasticity, and contractures. We report the occurrence of large subcapsular hematoma following ureteroscopy and discuss lessons we learn from this case.

Case report: A 48-year-old male patient with spina bifida underwent ureteroscopy with laser lithotripsy and ureteric stenting for left ureteric stone and staghorn calculus with hydronephrosis; laser lithotripsy was repeated after 3 months; both procedures were performed by a senior urologist and did not result in any complications. Ureteroscopic laser lithotripsy was performed 5 months later by a urological trainee; it was difficult to negotiate the scope as vision became poor because of bleeding (as a result of the procedure). Postoperatively, hematuria persisted; temperature was $39^{\circ} \mathrm{C}$. Cefuroxime was given intravenously followed by gentamicin for 5 days; hematuria subsided gradually; he was discharged home. Ten days later, this patient developed temperature, the urine culture grew Pseudomonas aeruginosa, and ciprofloxacin was given orally. Computed tomography (CT) of the urinary tract, performed 4 weeks after ureteroscopy, revealed a $9 \times 7 \mathrm{~cm}$ subcapsular collection on the left kidney compressing underlying parenchyma. Percutaneous drainage was not feasible because of severe curvature of spine. Isotope renogram revealed deterioration in left renal function from $30 \%$ to $17 \%$. Follow-up CT revealed reduction in the size of subcapsular hematoma, no hydronephrosis, and several residual calculi.

Conclusion: Risk of subcapsular hematoma following ureteroscopic lithotripsy can be reduced by avoiding prolonged endoscopy and performing ureteroscopy under low pressure. When a paraplegic patient develops features of infection after ureteroscopy, renal imaging should be carried out promptly. Extended perioperative medical care is required for spinal cord injury patients because of their propensity to develop sepsis. Antibiotics should be prescribed on the basis of recent urine microbiology results. Spinal cord injury patients should be treated by senior, experienced doctors and cared for in a spinal injuries unit in order to minimize complications. Keywords: spina bifida, paraplegia, ureteroscopy, lithotripsy, subcapsular hematoma, prevention

\section{Background}

Chronic neurogenic bladder dysfunction can cause fibrosis and bladder wall contractures that alter the anatomy of ureteral orifices and urethra. ${ }^{1}$ In addition, patients with spinal cord injury often suffer from lower extremity contractures making positioning in the lithotomy position difficult or impossible. ${ }^{2}$ Wolfe et $\mathrm{al}^{3}$ reviewed 29 patients with spinal cord injury, who underwent ureteroscopy with holmium:YAG laser lithotripsy for urolithiasis over a 15-year period. These authors were unable to identify or pass ureteroscope through the

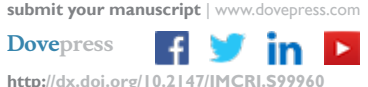


ureteral orifice in nine cases; perioperative complications were significantly higher at $29.9 \%$ with the majority due to urosepsis; however, subcapsular renal hematoma was not detected in any patient. Tepeler et $\mathrm{al}^{4}$ reviewed a total of 27 ureteroscopic procedures performed for urolithiasis in 21 renal units of 19 spinal cord injury patients. Postoperative complications were observed in six cases $(22.2 \%)$ : three major complications were urosepsis (n:1) and respiratory failure (n:2), which were observed postoperatively and required admission to the intensive care unit; 2 minor complications were hypotension, fever, and UTI and required medical treatment. These authors also did not report subcapsular renal hematoma. A review of 2,848 consecutive able-bodied persons undergoing ureteroscopic laser lithotripsy revealed that eleven patients $(0.4 \%)$ developed renal subcapsular hematoma. ${ }^{5}$

We report the first case of subcapsular renal hematoma in a paraplegic patient following ureteroscopic lithotripsy and discuss the lessons we learn from this incident. National Health Service (NHS), England, stipulates that patient safety incidents that could have or did harm a patient receiving NHS-funded care are reported, so lessons can be learned and any necessary action can be taken to prevent similar incidents from occurring in the future. ${ }^{6}$

\section{Case report}

A 48-year-old man, who was born with spina bifida and paraplegia waist downward, had been managing his bladder using a long-term indwelling urethral catheter. In January 2014 , he developed a temperature of $39^{\circ} \mathrm{C}$. Urine microbiology revealed Pseudomonas aeruginosa sensitive to ciprofloxacin; he was prescribed ciprofloxacin $500 \mathrm{mg}$ twice a day for 7 days. Ultrasound examination of urinary tract revealed bilateral renal calculi, with the largest calculus in the right kidney measuring $1 \mathrm{~cm}$ and a large staghorn calculus in the left kidney; no hydronephrosis was observed. Isotope renogram revealed a divided renal function of $70 \%$ for the right kidney and $30 \%$ for the left kidney. There was a persistent obstructive pattern in the left kidney with a slightly reduced tracer uptake in the left upper moiety of the duplex kidney. The left upper moiety accounted for $11 \%$ of function, while the left lower moiety $18 \%$ of function. On the static scan images, however, only the left upper moiety appeared obstructed for 30 minutes with persistent retention of tracer. CT revealed large staghorn calculus in the left kidney with moderately severe left hydronephrosis, pronounced in the upper pole. The left staghorn calculus measured $\sim 4 \mathrm{~cm}$ at its maximum diameter. A $13 \mathrm{~mm}$ calculus was noted in the left upper ureter. The left kidney measured $9.5 \mathrm{~cm}$ with diffuse mid- and upper-pole cortical thinning. Multiple calculi were present in the mid and lower poles of the right kidney; however, no bladder calculi were seen. Flexible uretero-renoscopy was performed rather than percutaneous nephrolithotomy because of the difficult anatomy secondary to spina bifida. It was made clear to the patient preoperatively that he would need multiple procedures.

In October 2014, left ureteroscopy with laser lithotripsy followed by insertion of left ureteric stent were carried out. A very tight stricture was found at the left ureteropelvic junction; the stricture was dilated sequentially and access sheath of size 12/14 French was used. After laser lithotripsy, $40 \%-50 \%$ of stones were fragmented; large amounts of stones were left behind at the end. The ureter, however, was clear and was stented with 8-French stent. In January 2015, repeat left ureterorenoscopy and laser lithotripsy were performed with a flexible ureteroscope (time taken was 3 hours). The majority of stone fragments were retrieved, while some fragments were left to pass; fragments were left in lower pole; the ureter was clear, and a 4.8-French stent was inserted in the left ureter. Ureteroscopy and laser lithotripsy were performed on both these occasions by the same senior and experienced urologist; there were no intraoperative or postoperative complications.

CT of kidney, ureters, bladder, performed 3 weeks after the second ureteroscopy, revealed some generalized shrinkage of left kidney with multifocal scarring and irregularity of its outline; there was a ureteric stent in situ on this side. There were three lower pole stones in individual calyces, two of them quite large, the largest measuring about $19 \mathrm{~mm}$ in diameter (Figure 1). There was some dilatation of the upper pole pelvicalyceal system despite the presence of the ureteric stent (Figure 2). There were no stones in the left ureter, but calcification was noted in the prostate, and small stone fragments were seen in the base of the bladder. The right kidney was of normal size with a small area of upper pole cortical scarring, but cortical thickness was otherwise reasonably maintained. There were, however, multiple upper and lower pole calyceal stones, the largest at the lower pole measuring about $14 \mathrm{~mm}$ and also a $1 \mathrm{~cm}$ stone in the renal pelvis.

Left JJ stent was removed easily 4 weeks after ureteroscopy. Stone analysis revealed struvite.

In April 2015, this patient's blood pressure was recorded as 143/97 mmHg. Recording of 24-hour blood pressure was not done, and no treatment was instituted. A sample of urine was sent for microbiology; the report was "mixed growth"; antibiotic sensitivity was not reported.

In June 3, 2015, left rigid ureterorenoscopy was performed by a urological trainee. Patient received gentamicin $240 \mathrm{mg}$ intravenously. The ureter was normal. A size 13/15, $46 \mathrm{~cm}$ 


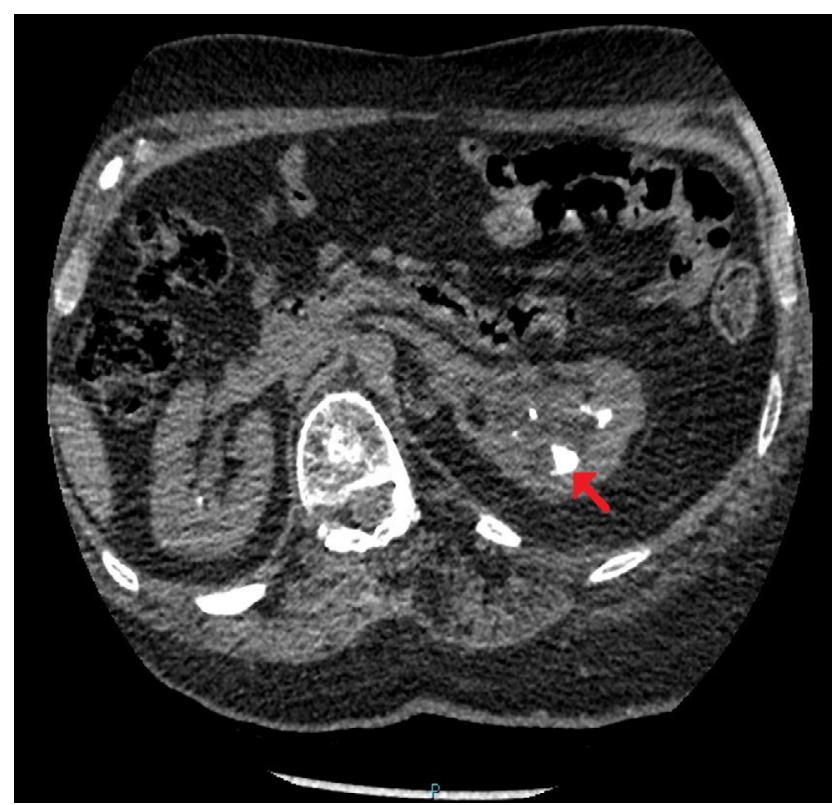

Figure I CT of urinary tract.

Note: Performed 3 weeks after the second ureteroscopy, axial section: residual stones in individual calyces, two of them quite large, the largest measuring $\sim 19 \mathrm{~mm}$ in diameter (arrow).

Abbreviation: $\mathrm{CT}$, computed tomography.

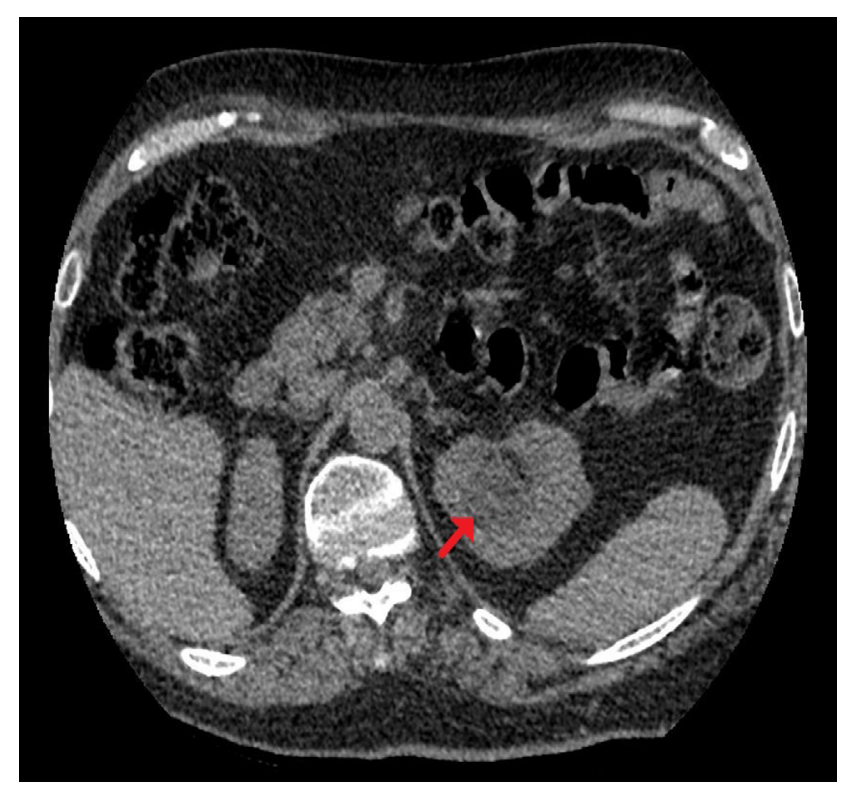

Figure 2 CT of urinary tract.

Note: Performed 3 weeks after the second ureteroscopy, axial section: there was some dilatation of the upper pole pelvicalyceal system despite the presence of the ureteric stent (arrow).

Abbreviation: $\mathrm{CT}$, computed tomography.

access sheath was used, and flexible ureteroscopy and laser lithotripsy were carried out. Fragments were removed with a basket. It was difficult to negotiate the scope into calyceal diverticulum; vision was poor because of bleeding; some fragments remained there. Then, right rigid ureteroscopy was performed. The ureter was normal. A size 13/15, $46 \mathrm{~cm}$ access sheath was used. Laser lithotripsy was performed and fragments were removed with a basket. There was a possible intrarenal mucosal perforation, and so a $4.8-\mathrm{Fr}, 26 \mathrm{~cm}$, JJ stent was inserted in both ureters. Surgery lasted for 2 hours and 40 minutes. During the beginning of surgery, blood pressure was $80 / 40 \mathrm{mmHg}$, then blood pressure remained stable at $90 / 50 \mathrm{mmHg}$. Patient developed frank hematuria and sinus tachycardia and was admitted to the critical care unit. He was hemodynamically stable, with a temperature of $39^{\circ} \mathrm{C}$. Hemoglobin: $116 \mathrm{~g} / \mathrm{L}(133-167)$; white blood cell count: $24.5 \times 10^{9} / \mathrm{L}(4.0-11.0)$; neutrophils: 22.6×10/L (1.8-7.5); INR: 1.2 (0.9-1.3); APTT: 32 seconds (20-30); APTT ratio: 1.3 (0.8-1.2); C-reactive protein: 137 $\mathrm{mg} / \mathrm{L}(0-10)$; creatinine: $64 \mu \mathrm{mol} / \mathrm{L}(0 \times 120)$. He was prescribed cefuroxime intravenously nocte and mane and transferred to the spinal unit the following day. In the spinal unit, this patient had a temperature of $38^{\circ} \mathrm{C}$; urine was dark red. Blood tests: INR: 1.1 ; hemoglobin: $120 \mathrm{~g} / \mathrm{L}$; white blood cell count: $20 \times 10^{9}$; neutrophils: $17.9 \times 10^{9}$; C-reactive protein: $168.1 \mathrm{mg} / \mathrm{L}$. He was prescribed gentamicin for 5 days. Hematuria subsided and he was discharged home. A week later, both ureteric stents were removed; gentamicin $160 \mathrm{mg}$ was administered prior to the procedure. Three days later, this patient developed temperature. CT of kidneys was requested. Hemoglobin: $128 \mathrm{~g} / \mathrm{L}$; white blood cell count: $9.6 \times 10^{9}$; C-reactive protein: $133.4 \mathrm{mg} / \mathrm{L}$. Urine culture: P. aeruginosa. He was prescribed ciprofloxacin $500 \mathrm{mg}$ twice a day for 5 days.

CT of urinary tract, performed 4 weeks after ureteroscopy, revealed a $9 \times 7 \mathrm{~cm}$ subcapsular collection on the left kidney compressing the underlying parenchyma (Figures 3 and 4). Minor perinephric fat stranding noted. A few residual stones/ fragments were seen in the lower pole calyces, the largest measuring $19 \mathrm{~mm}$ in size (Figure 5). Multiple residual stones were seen in the mid and lower pole calyces of the right kidney, the largest about $9 \mathrm{~mm}$. No ureteric or bladder stones. Chest X-ray revealed elevated left hemidiaphragm and minimal atelectasis in the left lower zone. Radiologist reviewed the CT images for the purpose of percutaneous drainage of subcapsular hematoma of the left kidney. The patient had severe curvature of spine, which made percutaneous access extremely difficult. Percutaneous access was made even more challenging because the spleen was located in the path. Therefore, percutaneous drainage was not carried out; the patient was managed conservatively by monitoring the body temperature, C-reactive protein, and white blood cell count.

He was prescribed ciprofloxacin $500 \mathrm{mg}$ twice a day for 5 days on empirical basis, as the laboratory did not carry out antibiotic sensitivity in the urine sample sent for culture. However, urine sample, which was sent 3 days later, showed the growth of Pseudomonas aeruginosa resistant to gentamicin and ciprofloxacin; therefore, ciprofloxacin was 


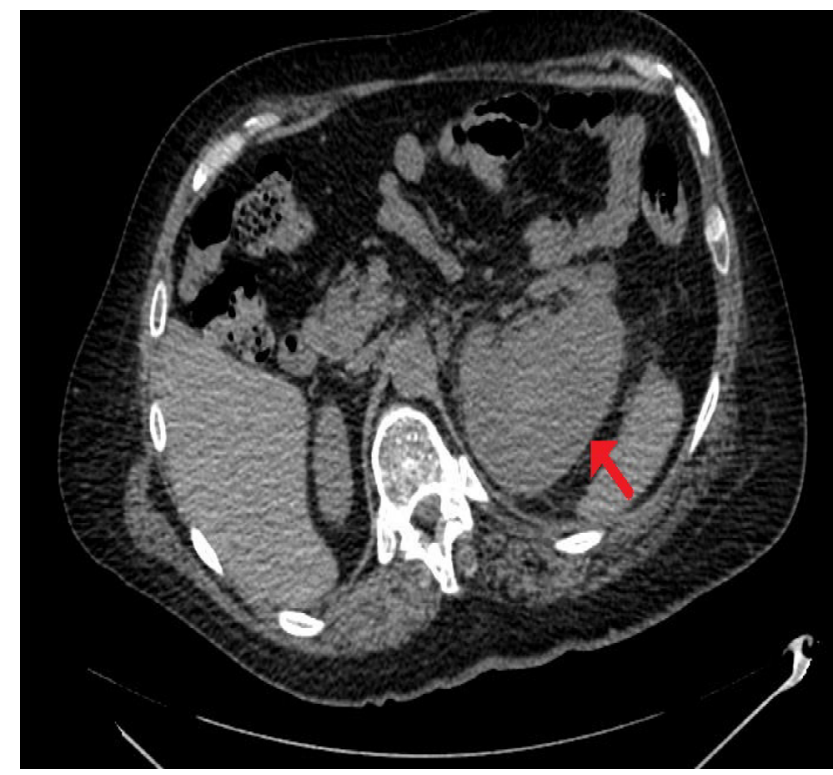

Figure $3 \mathrm{CT}$ of urinary tract.

Note: Performed 4 weeks after the third ureteroscopy, axial section: $9 \times 7 \mathrm{~cm}$ subcapsular collection on the left kidney compressing the underlying parenchyma present (arrow).

Abbreviation: CT, computed tomography.

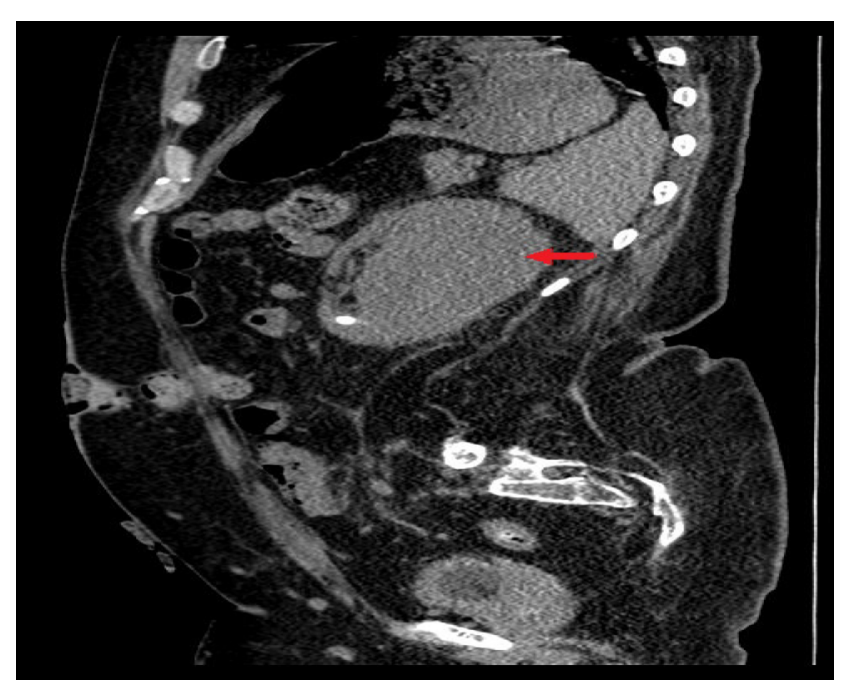

Figure $4 \mathrm{CT}$ of urinary tract.

Note: Performed 4 weeks after the third ureteroscopy, sagittal section: $9 \times 7 \mathrm{~cm}$ subcapsular collection on the left kidney compressing the underlying parenchyma present (arrow).

Abbreviation: CT, computed tomography.

discontinued. The patient remained well in himself. He was prescribed ferrous sulfate $200 \mathrm{mg}$ daily.

Isotope renogram, performed 8 weeks after the ureterorenoscopy, revealed deterioration in the left renal function because the study performed 7 months prior to the first ureteroscopy; the left kidney now contributed only $17 \%$ compared to the normal-looking right kidney, which contributed $83 \%$. Renographic analysis, however, showed both kidneys were draining spontaneously without obstruction; renographic

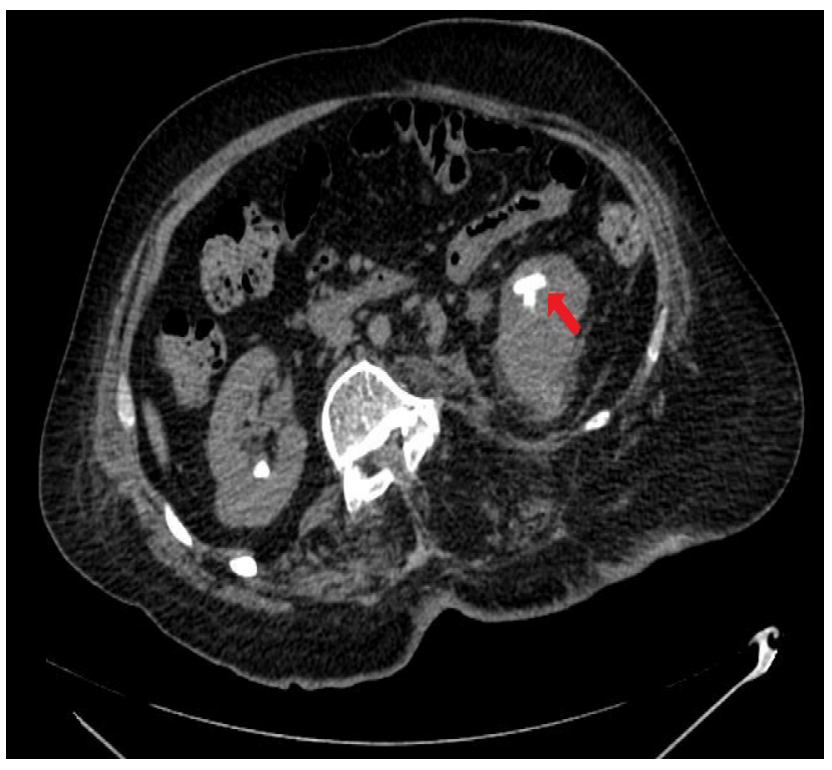

Figure $5 \mathrm{CT}$ of urinary tract.

Note: Performed 4 weeks after the third ureteroscopy, axial section: a few residual stones/fragments are seen in the lower pole calyces largest measuring $19 \mathrm{~mm}$ in size (arrow).

Abbreviation: CT, computed tomography.

drainage curve was normal on the right, with good drainage on the left - this being an improvement over the previous study.

Ultrasound scan of left kidney, performed 9 weeks after ureterorenoscopy, showed a residual hematoma $3.3 \mathrm{~cm}$ in depth. CT of kidney, ureters, bladder, performed 14 weeks after ureterorenoscopy, revealed left renal subcapsular collection to be much reduced in size, now measuring about $3 \times 2$ $\mathrm{cm}$ along the outer posterior aspect toward the upper renal pole (Figure 6). There was still some inflammatory stranding in the left perinephric fat,but no hydronephrosis. Several residual calculi still present in both kidneys.

Blood pressure was 146/93 mmHg; 24-hour mean blood pressure: $130 / 91 \mathrm{mmHg}$. This patient was prescribed ramipril $1.25 \mathrm{mg}$ daily. Four months after the third ureteroscopy, hemoglobin had increased to $157 \mathrm{~g} / \mathrm{L}$. Ethical approval for this case report was deemed not necessary by the Southport and Ormskirk Hospital NHS Trust.

\section{Discussion}

\section{Pathogenesis of subcapsular hematoma following ureteroscopy}

Ninomiya et $\mathrm{al}^{7}$ postulated that, in a hydronephrotic kidney, increased intrapelvic pressure causes kinking, stretching, and/or obstruction of the major vessels. After ureteroscopic lithotripsy, ureteric recanalization induces the sudden expansion and rupture of the attenuated, compressed, parenchyma and/or capsular vessels, thus resulting in subcapsular hematoma accumulation of fluid and blood in the subcapsular area of the kidney. 


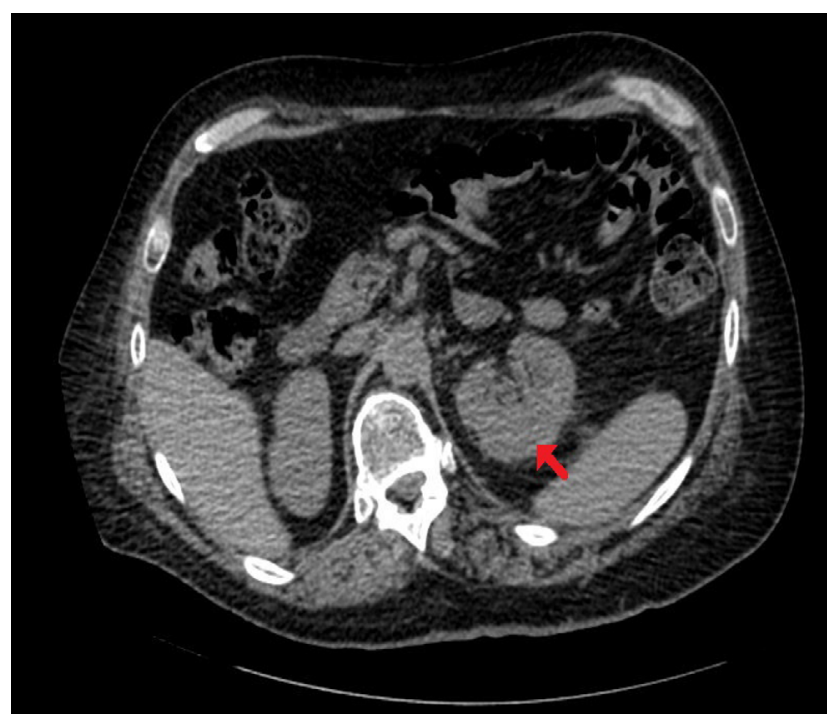

Figure 6 CT of kidneys.

Note: Performed 14 weeks after the third ureteroscopy, axial section, left renal subcapsular collection is much reduced in size, now measuring about $3 \times 2 \mathrm{~cm}$ along the outer posterior aspect toward the upper renal pole (arrow). Abbreviation: CT, computed tomography.

\section{Contributing factors to renal subcapsular hematoma}

Bai et $\mathrm{al}^{5}$ showed that four factors were significantly associated with the development of a subcapsular renal hematoma: stone size, degree of hydronephrosis, operation duration, and perfusion pressure of hydraulic irrigation.

Patients, who developed subcapsular renal hematoma, had larger stones, more severe ipsilateral hydronephrosis, longer operation duration, and higher perfusion pressure of hydraulic irrigation than patients who did not develop subcapsular renal hematoma. In our patient, the risk factors for developing subcapsular hematoma following ureterorenoscopy were as follows: 1) prior to the third ureteroscopy, the stone in the left kidney measured $19 \mathrm{~mm}$; 2) duration of surgery was 160 minutes, but our patient underwent bilateral ureterorenoscopy and laser lithotripsy; 3) dilatation of the upper pole pelvicalyceal system of the left kidney despite the presence of ureteric stent; and 4) during ureterorenoscopy, hydraulic irrigation was used as there was bleeding and the vision was poor. However, the pressure was kept $50 \mathrm{~cm}$ above the patient's bladder when supine and a ureteric access sheath was used, so the pressure was even less in the pelvicalyceal system.

\section{Prevention of subcapsular hematoma}

To prevent subcapsular hematoma, Bai et $\mathrm{al}^{5}$ suggested ureteroscopy should be performed under low pressure. These authors recommended following measures to lower the pressure by using only a minimal amount of irrigation by adjusting the tap, relieving the pressure regularly by stopping the flow and opening the tap, and inserting a transurethral 10-French catheter to lower the bladder pressure during surgery, especially in cases where the operation duration is expected to be long. Preoperative anti-infection and nephrostomy, as necessary, are additional precautions.

\section{Management of subcapsular hematoma}

As most subcapsular renal hematomas will ultimately heal spontaneously, conservative management is recommended. But, flank drainage will be required in patients who develop sepsis, flank pain, significant compromise in renal function, or in whom hematoma persist. In our patient, the size of subcapsular hematoma was greatly reduced spontaneously in 14 weeks without requiring surgical or percutaneous drainage.

\section{Risk factors for complications of surgery}

An important factor influencing complications of surgery is the surgeon's experience. Such a relationship has been shown in various surgical specialties. Hobbs et $\mathrm{l}^{8}$ reviewed intraoperative injuries in 33,309 laparoscopic cholecystectomies carried out in Western Australia between 1988 and 1998. The risk of intraoperative complications declined with increasing surgical experience. Skovrlj et $\mathrm{al}^{9}$ evaluated surgeon experience for perioperative complications in patients who underwent adult scoliosis surgery. The incidence of spinal cord complications and surgical site infection seemed to be different between the candidate members and active members of the Scoliosis Research Society. Candidate members had a twofold increase in the rate of spinal cord complications compared with active members, a finding that was statistically significant. Bilimoria et al ${ }^{10}$ carried out a systematic review of the literature to assess articles examining the impact of surgeon training, certification, and experience on outcomes in surgical oncology. These researchers found that American Board of Surgery-certified surgeons had better outcomes than noncertified surgeons. Of the two studies examining time since American Board of Surgery certification, both found that increased time was associated with better outcomes. Of the four studies that examined experience, three studies found that increased surgeon experience was associated with improved outcomes. Lawton and $\mathrm{Du}^{11}$ evaluated the neurosurgeon's surgical experience on a patient's outcome after an intraoperative rupture of an aneurysm. With increasing surgical experience, the number of ruptures during predissection and clip application, the mean duration of temporary clipping, and the surgical mortality rate all declined, whereas the number of patients experiencing a good outcome (Glasgow Outcome Scale score of 5 or 4 ) increased. Aminian et $\mathrm{al}^{12}$ observed that fellow participation was independently 
associated with higher rates of overall complications (odd's ratio $[\mathrm{OR}]=1.37,95 \%$ confidence interval $[\mathrm{CI}]: 1.16-1.63)$, serious complications ( $\mathrm{OR}=1.23,95 \% \mathrm{CI}$ : $1.00-1.52)$, surgical complications (OR $=1.42 ; 95 \% \mathrm{CI}: 1.17-1.73)$, and reoperation $(\mathrm{OR}=1.43,95 \% \mathrm{CI}: 1.10-1.87)$. These authors recommended promoting proficiency in surgical simulation laboratories in order to reduce postoperative complications and to ensure patient safety.

In this patient, a senior and experienced urologist performed the first two ureteroscopic lithotripsies. During the first ureteroscopy, there was very tight stricture of ureteropelvic junction and the patient had hydronephrosis. Even then, there were no intraoperative or postoperative complications. This case is a reminder that surgical procedures such as ureteroscopy have a higher risk in spinal cord injury patients, and surgeons should be aware of the risks of ureteroscopy in this unique group. To overcome or minimize the complications, patients should be assessed systematically and meticulously. All measures should be taken to prevent urosepsis following the procedure. ${ }^{13}$

\section{Prevention of sepsis following urological procedures in spinal cord injury patients}

This patient developed features of sepsis immediately after the third ureteroscopy despite receiving gentamicin $240 \mathrm{mg}$ during surgery and cefuroxime on the night of ureteroscopy. The temperature rose to $39^{\circ} \mathrm{C}$; white blood cell count was $24.5 \times 10^{9} / \mathrm{L}(4.0-11.0)$; and neutrophil count was $22.6 \times 10^{9} / \mathrm{L}$. In this patient, a sample of urine was sent for microbiology 6 weeks prior to the third ureteroscopy; the report was "mixed growth"; antibiotic sensitivity was not available. A prospective study in spinal cord injury patients showed that antibiotics should be prescribed on the basis of recent urine microbiologic test results, and empirical therapy with gentamicin should be avoided in patients with spinal cord injury who are scheduled to undergo urologic procedures. ${ }^{14}$

\section{Conclusion}

Risk of subcapsular hematoma following ureteroscopic lithotripsy can be reduced by avoiding prolonged endoscopy and performing ureteroscopy under low pressure. When a paraplegic patient develops features of infection after ureteroscopy, renal imaging should be carried out promptly. Extended perioperative medical care is required for spinal cord injury patients undergoing ureteroscopic lithotripsy because of their propensity to develop sepsis. Spinal cord injury patients should be treated by senior, experienced doctors and cared for in a spinal injuries unit in order to minimize complications.

\section{Acknowledgments}

The leading author is most grateful to Mr Stephen Cronin, President, Merseyside SIA and all members of Merseyside Spinal Injuries Association for payment of the article processing fee for this paper. The patient and his mother gave written informed consent for the publication of this case report and images of CT.

\section{Disclosure}

The authors report no conflicts of interest in this work.

\section{References}

1. Comperat E, Reitz A, Delcourt A, Capron F, Denys P, Chartier-Kastler E. Histologic features in the urinary bladder wall affected from neurogenic overactivity - a comparison of inflammation, oedema and fibrosis with and without injection of botulinum toxin type A. Eur Urol. 2006;50(5):1058-1064.

2. Ramsey S, McIlhenny C. Evidence-based management of upper tract urolithiasis in the spinal cord-injured patient. Spinal Cord. 2011; 49(9):948-954.

3. Wolfe T, Klausner AP, Goetz LL, King AB, Hudson T, Gater DR. Ureteroscopy with laser lithotripsy for urolithiasis in the spinal cord injury population. Spinal Cord. 2013;51(2):156-160.

4. Tepeler A1, Sninsky BC, Nakada SY. Flexible ureteroscopic laser lithotripsy for upper urinary tract stone disease in patients with spinal cord injury. Urolithiasis. 2015;43(6):501-505.

5. Bai J, Li C, Wang S, et al. Subcapsular renal haematoma after holmium:yttrium-aluminum-garnet laser ureterolithotripsy. BJUInt. 2012; 109(8):1230-1234.

6. NHS. Reporting Patient Safety Incidents. England, UK: National Health Service. Available from: https://www.england.nhs.uk/patientsafety/ report-patient-safety/.

7. Ninomiya $H$, Inomata $T$, Ogihara K. Microvasculature of hydronephrotic kidneys in KK-A(Y) mice. J Vet Med Sci. 2000;62(10):1093-1098.

8. Hobbs MS, Mai Q, Knuiman MW, Fletcher DR, Ridout SC. Surgeon experience and trends in intraoperative complications in laparoscopic cholecystectomy. Br J Surg. 2006;93(7):844-853.

9. Skovrlj B, Cho SK, Caridi JM, Bridwell KH, Lenke LG, Kim YJ. Association between surgeon experience and complication rates in adult scoliosis surgery: a review of 5117 cases from the Scoliosis Research Society Database 2004-2007. Spine. 2015;40(15):1200-1205.

10. Bilimoria KY, Phillips JD, Rock CE, Hayman A, Prystowsky JB, Bentrem DJ. Effect of surgeon training, specialization, and experience on outcomes for cancer surgery: a symptomatic review of the literature. Ann Surg Oncol. 2009;16(10):1799-1808.

11. Lawton MT, Du R. Effect of the neurosurgeon's surgical experience on outcomes from intraoperative aneurysmal rupture. Neurosurgery. 2005;57(1):9-15.

12. Aminian A, Chaudhry RM, Khorgami Z, et al. A challenge between trainee education and patient safety: does fellow participation impact postoperative outcomes following bariatric surgery? Obes Surg. Epub January 27, 2016.

13. Kocaaslan R, Bagcioglu M, Karadag MA, Demir A. Re: Flexible ureteroscopic laser lithotripsy for upper urinary tract stone disease in patients with spinal cord injury. Urolithiasis. 2016;44(2):191-192.

14. Vaidyanathan S, Soni BM. Antibiotic therapy for patients with spinal cord injury undergoing urologic procedures. Adv Ther. 2006;23(1):92-97. 
International Medical Case Reports Journal

The International Medical Case Reports Journal is an international, peer-reviewed open-access journal publishing original case reports from all medical specialties. Previously unpublished medical posters are also accepted relating to any area of clinical or preclinical science. Submissions should not normally exceed 2,000 words or
4 published pages including figures, diagrams and references. The manuscript management system is completely online and includes a very quick and fair peer-review system, which is all easy to use. Visit $\mathrm{http}: / /$ www.dovepress.com/testimonials.php to read real quotes from published authors.

Submit your manuscript here: https://www.dovepress.com/international-medical-case-reports-journal-journal 